\title{
Microbial Limit
}

National Cancer Institute

\section{Source}

National Cancer Institute. Microbial Limit. NCI Thesaurus. Code C134256.

Tests for the estimation of the number of viable aerobic microorganisms present and for the freedom from designated microbial species in the pharmaceutical articles of all kinds, from raw materials to the finished forms. 